\title{
ASUPAN TINGGI NATRIUM DAN BERAT BADAN LAHIR SEBAGAI FAKTOR RISIKO KEJADIAN HIPERTENSI OBESITAS PADA REMAJA AWAL
}

\author{
Lutfiana Amirullah Fatta, Muhammad Sulchan ${ }^{*}$ \\ Program Studi Ilmu Gizi Fakultas Kedokteran Universitas Diponegoro \\ Jl.Dr.Sutomo No.14, Semarang, Telp (024) 8453708, Email : gizifk@undip.ac.id
}

\begin{abstract}
Background: Obesity Hypertension does not only occur in adults or elderly, but also can occur on adolescents. Obesity Hypertension risk factors on adolescents as well as risk factors for obesity and hypertension. High-sodium intake and birth weight are two of the several risk factors for obesity hypertension. The purpose of this study was to determine magnitude of risk factors of high-sodium intake and birth weight on obesity hypertension occurance on early adolescence.

Method: The study was carried out in SMP 3, SMP 30, SMP Kesatrian 2, and Madrasah Al-Khoiriyah. The design of this study is case-control with the amount of subjects are 72 consist of 36 cases and 36 controls. The subjects were selected that met the inclusion criteria. Data sodium intake is obtained by interview using Food Frequency Questionnaire last one month. Data on birth weight is obtained from interview with parents which supported by the record of KMS / KIA. Height measurements using microtoise, weight using digital scales, waist circumference using a tape measure, and blood pressure using a sphygmomanometer.

Results: The prevalence of obesity hypertension is $7.5 \%$. In this study, it is found that there is a significant correlation between high-sodium intake $(p=0.042 ;$ OR $=3.5)$ birth weight $(p=0.012 ;$ OR $=3.7)$ on obesity hypertension occurance on early adolescence.

Conclusion: High-sodium intake and birth weight are risk factor of obesity hypertension on early adolescence. Major risk factors of high-sodium intake and birth weight are respectively 3.5 times and 3.7 times
\end{abstract}

Key words: early adolescents; obesity hypertension; high-sodium intake; birth weight

\begin{abstract}
ABSTRAK
Latar belakang: Hipertensi obesitas tidak hanya terjadi pada orang dewasa atau usia lanjut, tapi juga dapat terjadi pada remaja. Faktor risiko hipertensi obesitas pada remaja sama halnya dengan faktor risiko obesitas dan hipertensi. Asupan tinggi natrium dan berat badan lahir merupakan dua faktor risiko dari sekian faktor risiko hipertensi obesitas. Tujuan dari penelitian ini adalah untuk mengetahui besarnya risiko faktor asupan tinggi natrium dan berat badan lahir terhadap kejadian hipertensi obesitas pada remaja awal.

Metode: Penelitian dilakukan di SMP Negeri 3, SMP Negeri 30, SMP Kesatrian 2, dan Madrasah Al-Khoiriyah. Desain penelitian case-control dengan jumlah subyek 72 yang terdiri dari 36 kasus dan 36 kontrol. Subyek yang dipilih adalah yang memenuhi kriteria inklusi. Data asupan natrium didapatkan dengan wawancara menggunakan Food Frequency Questionnaire 1 bulan terakhir. Data berat badan lahir diperoleh dari wawancara dengan orang tua yang didukung dengan catatan KMS/KIA. Pengukuran tinggi badan menggunakan microtoise, berat badan menggunakan timbangan digital, lingkar pinggang menggunakan pita ukur, dan tekanan darah menggunakan sphygmomanometer.

Hasil: Prevalensi hipertensi obesitas sebesar 7,5\%. Pada penelitian ini ditemukan hubungan yang bermakna antara asupan tinggi natrium $(p=0,042 ; O R=3,5)$ dan berat badan lahir $(p=0,012 ; O R=3,7)$ terhadap kejadian hipertensi obesitas pada remaja awal.

Simpulan: asupan tinggi natrium dan berat badan lahir merupakan faktor risiko kejadian hipertensi obesitas pada remaja awal. Besar risiko faktor asupan tinggi natrium dan berat badan lahir masing-masing adalah 3,5 kali dan 3,7 kali.
\end{abstract}

Kata kunci: remaja awal; hipertensi obesitas; asupan tinggi natrium; berat badan lahir

\section{PENDAHULUAN}

Masa remaja merupakan masa peralihan dari masa kanak-kanak menuju dewasa. Remaja bukan lagi kanak-kanak, namun belum dapat dikatakan dewasa. Masa remaja dibagi atas empat bagian, yaitu masa pra remaja (10-12 tahun), masa remaja awal (12-15 tahun), masa remaja pertengahan (15-18 tahun) dan masa remaja akhir (18-21 tahun) ${ }^{1}$.

Status gizi remaja secara tidak langsung dipengaruhi oleh kebiasaan makan. Aktivitas remaja umumnya banyak dilakukan di luar rumah

${ }^{*}$ Penulis Penanggungjawab 
sehingga sering dipengaruhi oleh teman sebaya, termasuk dalam hal pemilihan makanan. Pemilihan makan tidak lagi didasarkan pada kandungan gizi tetapi sekadar bersosialisasi, untuk kesenangan dan agar tidak kehilangan status ${ }^{2}$. Umumnya remaja memilih makanan yang tidak membutuhkan waktu yang lama untuk diolah. Makanan tersebut dikenal dengan istilah "fast food". Fast food banyak dijumpai di kafe, restoran, maupun kantin sekolah dan identik dengan porsi yang besar dan kandungan natrium yang tinggi. Kebiasaan makan remaja tersebut berkontribusi terhadap kejadian obesitas yang akan menimbulkan terjadinya hipertensi obesitas. Remaja dikatakan obesitas jika IMTnya $\geq$ persentil $95^{3}$.

Hipertensi sebagai outcome obesitas tidak lagi dipandang sebagai masalah pada orang dewasa saja. Hipertensi ditemukan mulai dari masa kanakkanak dan remaja. Sebanyak 5\% anak-anak atau tujuh juta anak di Amerika Serikat ditemukan memiliki tekanan darah yang tinggi ${ }^{4}$. Dengan meningkatnya usia, prevalensi hipertensi juga meningkat ${ }^{4}$. Namun, tidak semua individu obesitas mengalami hipertensi ${ }^{5}$. Sorof et al menemukan prevalensi hipertensi sistolik diantara remaja obese sebanyak 50\% sedangkan pada remaja nonobesitas sebanyak $30 \%{ }^{6}$.

Hipertensi berkaitan dengan asupan tinggi natrium. Tekanan darah populasi dengan diet tinggi natrium ditemukan lebih tinggi dibanding populasi dengan diet rendah natrium ${ }^{7}$. Faktor risiko hipertensi dan obesitas yang lain yaitu berat badan lahir ${ }^{8}$. Barker mengemukakan bahwa berat badan lahir rendah berhubungan dengan kejadian beberapa penyakit kardiovaskular yang disebabkan karena undernutrisi di masa kehidupan janin, salah satunya adalah hipertensi ${ }^{9}$. Anak-anak yang mengalami hipertensi umumnya memiliki ukuran tubuh yang kecil ketika lahir, tetapi mengalami peningkatan berat badan di akhir masa kanak$\operatorname{kanak}^{10}$. Namun, penelitian di Cina menunjukkan bahwa selain berat badan lahir < 2500gr, berat badan lahir $\geq 3500$ gr juga berhubungan dengan risiko obesitas dan hipertensi ${ }^{11}$.

Hipertensi obesitas dapat mengakibatkan morbiditas bahkan mortalitas kardiovaskular. Pencegahan awal perlu dilakukan untuk meningkatkan kualitas hidup dan biaya yang berhubungan dengan management medis hipertensi dan komplikasinya ${ }^{4}$. Pencegahan ditujukan untuk mengontrol epidemi obesitas sekarang ini dan lebih efektif pada anak dibandingkan pada orang dewasa. Upaya pencegahan maupun pengelolaan secara terpadu dapat dilakukan dengan mengetahui penyebab masalah gizi ini terlebih dahulu ${ }^{12}$. Kejadian baik obesitas maupun hipertensi obesitas, sebaiknya di deteksi lebih dini untuk mencegah akibat yang lebih buruk, seperti morbiditas dan mortalitas kardiovaskular. Prevalensi berat badan lahir tinggi ( $\geq 4000$ gram) pada tahun 2010 mencapai $6,4 \%{ }^{13}$. Upaya pencegahan berat badan lahir tinggi perlu dilakukan dalam rangka pencegahan hipertensi obesitas.

Obesitas yang disertai dengan peningkatan tekanan darah sistolik dan atau diastolik disebut hipertensi obesitas. Penelitian di Semarang pada tahun 2006 menunjukkan prevalensi hipertensi obesitas sebesar $6,3 \%^{14}$. Faktor risiko hipertensi obesitas sama halnya dengan faktor risiko obesitas dan hipertensi. Asupan tinggi natrium merupakan faktor risiko terjadinya hipertensi dan berat badan lahir berhubungan dengan risiko obesitas dan hipertensi ${ }^{7,11}$. Penelitian ini bertujuan untuk melihat besar risiko faktor asupan tinggi natrium dan berat badan lahir sebagai faktor risiko hipertensi obesitas pada remaja awal.

\section{METODE PENELITIAN}

Penelitian ini merupakan penelitian gizi masyarakat yang dilakukan di 5 SMP di Kota Semarang pada bulan Mei sampai Juni 2012, menggunakan desain case control dengan pendekatan retrospektif.

Populasi penelitian adalah remaja awal usia 12-14 tahun di kota Semarang. Sampel dengan teknik cluster sampling sehingga terpilih 5 SMP dari 212 SMP. Selanjutnya dilakukan Proportional Random Sampling sampai akhirnya terpilih SMP Negeri 3, SMP Negeri 30, SMP Kesatrian 2, SMPN 10 Nopember 2, dan Madrasah AlKhoiriyah dari 2 SMP negeri, 2 SMP swasta dan 1 Madrasah Tsanawiyah. Penelitian lanjutan dilakukan di 4 SMP. SMPN 10 Nopember 2 dieksklusi karena pertimbangan lokasi yang cukup jauh dan prevalensi hipertensi obesitas di SMP tersebut sangat rendah, yaitu $0,027 \%$. Besar sampel minimal masing-masing berjumlah 38 kasus dan 38 kontrol, ditentukan dengan menggunakan rumus kasus kontrol berpasangan ${ }^{15}$. Namun, subyek yang diteliti dalam penelitian ini hanya 36 kasus dan 36 kontrol karena kelompok kasus yang memenuhi kriteria inklusi dan tidak dapat dieksklusi berjumlah 36 subyek. Kontrol dipilih secara matching berdasarkan usia dan jenis kelamin. Kelompok kasus adalah subjek dengan hipertensi obesitas sedangkan kelompok kontrol adalah subjek nonhipertensi obesitas. 
Kriteria inklusi yang digunakan meliputi berusia 12-14 tahun, terdaftar sebagai siswa di SMP Negeri 3, SMP Negeri 30, SMP Kesatrian 2, SMPN 10 Nopember 2, dan Madrasah AlKhoiriyah dan telah diskrining, memiliki data berat badan lahir baik menurut catatan KMS, buku KIA atau pengakuan orang tua serta tidak ada riwayat penyakit kronis.

Variabel dependen adalah hipertensi obesitas. Hipertensi obesitas adalah keadaan dimana hasil skrining menunjukkan BMI berdasarkan umur dan jenis kelamin $\geq$ persentil 95 disertai nilai tekanan darah sistolik dan/atau tekanan darah diastolik $\geq$ persentil ke- $95^{16}$. Variabel independent adalah berat badan lahir dan asupan tinggi natrium. Berat badan lahir adalah berat badan ketika baru lahir tanpa memandang masa gestati sampai 24 jam setelah kelahiran ${ }^{17}$. Penelitian ini menggunakan $c u t$ off point $\geq 3500$ gr sebagai berat badan lahir tinggi. Asupan tinggi natrium adalah total asupan natrium dari makanan/minuman mengandung natrium yang dikonsumsi subjek per hari dalam (mg) yang $>2200 \mathrm{mg} / \mathrm{hr}$ untuk usia 9-13 tahun dan $>2300 \mathrm{mg} / \mathrm{hr}$ untuk usia 14-18 tahun $^{18}$.

Data primer yang dikumpulkan meliputi identitas sampel, tinggi badan, berat badan, lingkar pinggang, denyut nadi, tekanan darah, asupan natrium, serta berat badan lahir. Pengukuran tinggi badan dilakukan dengan menggunakan microtoise, berat badan menggunakan timbangan digital, dan lingkar pinggang menggunakan pita ukur ${ }^{19}$. Penentuan BMI/U menggunakan software WHO Anthroplus. Pengukuran tekanan darah menggunakan sphygmomanometer. Penentuan status tekanan darah (hipertensi/nonhipertensi) subjek menggunakan tabel tingkat tekanan darah berdasarkan jenis kelamin, usia dan tinggi badan ${ }^{16}$. Data asupan natrium didapatkan dengan wawancara menggunakan tabel Food Frequency Questionnaire $(F F Q)$ dalam 1 bulan terakhir, sedangkan data berat badan lahir diperoleh dari wawancara dengan orang tua yang didukung dengan catatan KMS/KIA. Pengolahan dan analisis data menggunakan komputer. Analisis faktor risiko (variabel bebas) terhadap variabel terikat menggunakan uji Chi Square, dimana jika $p$ value $<0,05$ dikatakan bermakna ${ }^{20}$. Analisis konsumsi zat gizi menggunakan Nutrisurvey.

\section{HASIL PENELITIAN \\ Karakteristik Subyek Penelitian}

Hasil skrining awal melibatkan 1186 subyek yang berasal dari 5 SMP di Semarang dengan melakukan pengukuran berat badan, tinggi badan, lingkar pinggang, denyut nadi, dan tekanan darah. Hasil skrining menunjukkan bahwa $355(30,03 \%)$ subyek termasuk hipertensi, $155(13,11 \%)$ subyek adalah obesitas, dan 89(7,52\%) subyek termasuk dalam hipertensi obesitas. Sampel minimal pada penelitian ini sebanyak 38 kasus dan 38 kontrol. Namun, hanya 36 kasus dan 36 kontrol dari 4 SMP yang memenuhi kriteria inklusi dan tidak dapat dieksklusi sehingga hanya melibatkan 72 subyek. Kelompok kasus terdiri dari subyek dengan hipertensi obesitas, sedangkan kelompok kontrol terdiri dari subyek yang tidak mengalami obesitas maupun hipertensi. Karakteristik subyek penelitian pada kelompok kasus dan kontrol ditampilkan pada tabel 1 .

Tabel 1. Karakteristik subyek penelitian

\begin{tabular}{cccc}
\hline Karakteristik & Kasus $(\mathrm{n}=36)$ & Kontrol $(\mathrm{n}=36)$ & Total \\
\cline { 2 - 3 } Jenis Kelamin, $\mathrm{n}(\%)$ & & & \\
$\quad$ Laki-laki & $22(61,1 \%)$ & $22(61,1 \%)$ & $44(61,1 \%$ \\
$\quad$ Perempuan & $14(38,9 \%)$ & $14(38,9 \%)$ & ) \\
Usia (tahun), n(\%) & & & $28(38,9 \%$ \\
$\quad 12$ tahun & $4(11,1 \%)$ & $4(11,1 \%)$ & ) \\
13 tahun & $17(47,2 \%)$ & $17(47,2 \%)$ & \\
14 tahun & $15(41,7 \%)$ & $15(41,7 \%)$ & $8(11,1 \%)$ \\
Rerata Tekanan Darah, mmHg & & & 34 \\
$\quad$ Sistolik & $128,89 \pm 14,8$ & $101,94 \pm 12,20$ & $(47,2 \%)$ \\
$\quad$ Diatolik & 3 & $63,47 \pm 5,83$ & $30(41,7 \%$ \\
Rerata BMI, persentil & $81,52 \pm 8,17$ & $36,17 \pm 22,21$ & ) \\
& $98,25 \pm 1,48$ & & \\
\hline
\end{tabular}

Pada tabel 1 dapat dilihat bahwa pemilihan kontrol dilakukan dengan matching berdasarkan jenis kelamin dan usia. Subyek penelitian terdiri dari 44 anak laki-laki $(61,1 \%)$ dan 28 anak 
perempuan $(38,9 \%)$. Rerata umur subyek adalah $13,3 \pm 0,66$ tahun dengan umur termuda adalah 12 tahun dan tertua adalah 14 tahun. Subyek berusia 12 tahun sebanyak 8 anak $(11,1 \%), 13$ tahun sebanyak 34 anak $(47,2 \%)$, dan 14 tahun sebanyak 30 anak $(41,7 \%)$. Rerata tekanan darah sistolik pada kelompok kasus sebesar 128,89 $\pm 14,83$ mmHg dengan nilai terendah 110 dan tertinggi 170 mmHg, sedangkan pada kelompok kontrol sebesar $101,94 \pm 12,20 \mathrm{mmHg}$ dengan nilai terendah 80 dan tertinggi $120 \mathrm{mmHg}$. Rerata tekanan darah diastolik kelompok kasus sebesar 81,52 $\pm 8,17$ $\mathrm{mmHg}$ dengan nilai terendah 60 dan tertinggi 100 mmHg, sedangkan pada kelompok kontrol sebesar $63,47 \pm 5,83 \mathrm{mmHg}$ dengan nilai terendah 50 dan tertinggi $70 \mathrm{mmHg}$. Pada kelompok kasus, rerata BMI sebesar 98,25 $\pm 1,48$ persentil dengan nilai terendah 95,2 dan tertinggi 100 persentil, sedangkan pada kelompok kontrol sebesar $36,17 \pm 22,21$ persentil dengan nilai terendah 6 dan tertinggi 83 persentil.

\section{Berat Badan Lahir sebagai Faktor Risiko Hipertensi Obesitas}

Tabel 2 berikut menunjukkan hubungan dan besar risiko secara bivariat antara berat badan lahir sebagai faktor risiko terjadinya hipertensi obesitas pada remaja awal. Rerata berat badan lahir subyek yaitu $3,20 \pm 0,43 \mathrm{~kg}$ dengan berat badan lahir terendah $2,5 \mathrm{~kg}$ dan tertinggi $4,5 \mathrm{~kg}$.

Tabel 2. Tabulasi silang berat badan lahir berdasarkan status gizi

\begin{tabular}{llllll}
\hline Karakteristik & Kasus $(\mathrm{n}=36)$ & $\begin{array}{l}\text { Kontrol } \\
(\mathrm{n}=36)\end{array}$ & Rerata & $\mathrm{p}$ & OR(95\%CI) \\
\cline { 2 - 3 } $\begin{array}{c}\text { Berat Badan Lahir } \\
\quad \text { Tinggi }\end{array}$ & $17(47,2 \%)$ & & & \\
$\quad$ Normal & $19(52,8 \%)$ & $29(80,6 \%)$ & $3,20 \pm 0,43$ & 0,012 & 3,7 \\
$\quad$ & & & & $(1,29-10,62)$ \\
\hline
\end{tabular}

Pada tabel 2 didapatkan hasil bahwa berat badan lahir yang tinggi berisiko 3,7 kali untuk terjadi hipertensi obesitas $(p=0,012)$. Subyek dengan berat badan lahir normal sebanyak $48(66,7 \%)$ subyek sedangkan berat badan lahir tinggi sebanyak 24(33,3\%) subyek. Sebanyak
17(70,83\%) subyek dengan berat badan lahir tinggi mengalami hipertensi obesitas.

\section{Asupan Natrium sebagai Faktor risiko Hipertensi Obesitas}

Tabel 3. Tabulasi silang asupan natrium berdasarkan status gizi

\begin{tabular}{ccllll}
\hline Karakteristik & Kasus $(\mathrm{n}=36)$ & $\begin{array}{l}\text { Kontrol } \\
(\mathrm{n}=36)\end{array}$ & Rerata & $\mathrm{p}$ & $\mathrm{OR}(95 \% \mathrm{CI})$ \\
\cline { 2 - 3 } Natrium & $11(30,6 \%)$ & $4(11,1 \%)$ & $1450,1 \pm 841,7$ & 0,042 & 3,5 \\
$\quad$ Tinggi & $25(69,4 \%)$ & $32(88,9 \%)$ & & & $(1,00-12,38)$ \\
$\quad$ Normal & & &
\end{tabular}

Pada tabel 3 didapatkan hasil bahwa asupan natrium yang tinggi berisiko 3,5 kali untuk terjadi hipertensi obesitas $(\mathrm{p}=0,042)$. Rerata asupan natrium subyek yaitu $1450,1 \pm 841,7 \mathrm{mg} / \mathrm{hr}$ dengan asupan natrium terendah sebesar $118,1 \mathrm{mg} / \mathrm{hr}$ dan tertinggi sebesar $3260,70 \mathrm{mg} / \mathrm{hr}$. Asupan natrium dikatakan normal jika $<2200 \mathrm{mg} / \mathrm{hr}$ untuk usia 913 tahun dan <2300 untuk usia 14-18 tahun ${ }^{15}$. Subyek dengan asupan natrium normal sebanyak $57(79,17 \%)$ subyek sedangkan asupan natrium yang tinggi sebanyak 15(20,83\%) subyek. Sebanyak 11(73,33 \%) subyek dengan asupan natrium yang tinggi mengalami hipertensi obesitas.

\section{PEMBAHASAN}

Hasil skrining awal melibatkan 1186 subyek yang berasal dari 5 SMP di Semarang dengan melakukan pengukuran berat badan, tinggi badan, lingkar pinggang, denyut nadi, dan tekanan darah. Hasil skrining menunjukkan bahwa $355(30,03 \%)$ subyek termasuk hipertensi, $155(13,11 \%)$ subyek adalah obesitas, dan $89(7,52 \%)$ subyek termasuk dalam hipertensi obesitas. Angka tersebut lebih tinggi dibandingkan hasil penelitian secara cross sectional di Semarang pada tahun 2006 yang melaporkan bahwa kejadian hipertensi obesitas sebesar $6,3 \%^{14}$. Tingginya kejadian hipertensi pada penelitian ini menunjukkan bahwa hipertensi merupakan 
masalah yang banyak terjadi pada usia pubertas, terutama kejadian hipertensi pada remaja dengan obesitas dan semakin lama angkanya semakin meningkat.

Berat badan lahir dikategorikan tinggi jika $\geq 4000$ gr. Tidak ada cut off point yang mengatakan bahwa berat badan lahir $\geq 3500$ gr dikatakan tinggi. Namun, berat badan lahir $\geq 3500$ gr ditemukan berisiko terhadap kejadian hipertensi dan obesitas sehingga dalam penelitian ini menggunakan batasan berat badan lahir $\geq 3500$ gr sebagai berat badan lahir yang tinggi. ${ }^{11}$. Pada penelitian ini, subyek dengan berat badan lahir $\geq$ 3500 gr ditemukan berisiko 3,7 kali lebih besar mengalami hipertensi obesitas $(p=0,012)$. Pada kelompok kasus sebanyak 16 subyek $(64 \%)$ dari 25 subyek dengan asupan natrium normal ditemukan memiliki berat badan lahir yang tinggi. Penelitian ini sejalan dengan penelitian JY Tian yang menemukan bahwa berat badan lahir $\geq 3500$ gr merupakan faktor risiko obesitas $(\mathrm{RP}=1,31)$ dan hipertensi $(R P=1,98)^{11}$. Hipertensi obesitas dapat terjadi pada orang dengan berat badan lahir tinggi awalnya melibatkan mekanisme "pemrograman genetik" untuk terjadinya obesitas dan kemudian obesitas yang tidak ditangani lebih lanjut akan meningkatkan risiko hipertensi. Pemrograman tersebut dipengaruhi oleh faktor lingkungan intrauterin yang nantinya akan berpengaruh pada janin ${ }^{21,22}$.

Pemrograman janin tergantung kondisi ibu. Pemrograman janin dan komposisi tubuh berasal dari kontrol metabolik ibu selama kehamilan. Ibu yang mengalami diabetes pada trimester kedua kehamilan menyebabkan perpindahan glukosa yang berlebihan dari ibu ke janin. Proses ini menyebabkan hiperglikemia dan mengubah struktur dan fungsi pankreas pada bayi yang dikandung yang mengarah ke makrosomia dan tingginya lemak tubuh sehingga meningkatkan risiko obesitas. Hal tersebut menunjukkan bahwa transfer energi selama kehamilan berkaitan dengan berat badan yang lebih tinggi dan selanjutnya komposisi tubuh. Hal tersebut juga berkaitan dengan diet ibu sehingga peran gizi dalam pemrograman komposisi tubuh disini sangat penting. Komponen penting gizi di awal kehidupan tidak hanya metabolisme ibu dan cara pemberian makan pada bayi, tetapi makanan postnatal bagi bayi prematur, jadwal pemberian makanan setelah kelahiran dan jadwal penyapihan. Seperti gizi ibu selama kehamilan, beban glikemik diet bayi juga menjadi penting.
Pertumbuhan post-natal dan komposisi tubuh selanjutnya merupakan re-evaluasi bukti mengenai "pemrograman" penyakit di masa dewasa dan sangat kuat menunjukkan bahwa peningkatan berat badan setelah kelahiran merupakan komponen penting dari proses tersebut. Hubungan antara berat badan lahir dan distribusi lemak yang dihasilkan oleh laju pertumbuhan postnatal, berkaitan juga dengan pola pertumbuhan prenatal. Bayi dengan berat badan lebih besar memprediksi peningkatan tinggi badan, berat badan, massa tubuh tanpa lemak, massa lemak tubuh dan lingkar pinggang pada masa remaja akhir $^{23}$.

Selama ini yang kita ketahui bahwa berat badan lahir rendah yang berhubungan dengan risiko hipertensi sesuai dengan hipotesis Barker yang menyatakan bahwa berat badan lahir rendah berhubungan dengan kejadian beberapa penyakit kardiovaskular yang disebabkan karena undernutrisi di masa kehidupan janin, salah satunya adalah hipertensi ${ }^{9}$ Berat badan lahir merupakan penanda faktor genetik dan lingkungan prenatal ${ }^{24}$. Gangguan nutrisi pada ibu disertai plasenta yang abnormal dan gangguan aliran darah di janin menyebabkan gangguan nutrisi pada janin. Gangguan tersebut menyebabkan gangguan pertumbuhan dan kematangan organ sehingga bayi yang lahir memiliki ukuran tubuh dan berat badan yang kecil. Anak-anak yang memiliki ukuran tubuh yang kecil ketika lahir, mengalami pertumbuhan yang lambat di masa awal kehidupan, tetapi mengalami peningkatan berat badan di akhir masa kanak-kanak ${ }^{10}$. Jika tidak dapat mempertahankan berat badan optimal akan meningkatkan risiko hipertensi di kemudian hari.

Penjelasan tersebut menunjukkan bahwa kejadian berat badan lahir rendah maupun tinggi harus dicegah mengingat kemungkinan terjadinya hipertensi pada anak yang obesitas. Selain itu, bermunculan juga penyakit metabolik lainnya, salah satunya adalah diabetes mellitus. Penelitian di Taiwan pada tahun 2003 menunjukkan bahwa subyek dengan berat badan lahir tinggi $(\geq 4000 \mathrm{gr})$ berisiko tinggi mengalami diabetes mellitus tipe 2 dibanding subyek dengan berat badan lahir antara 3000 sampai $3500 \operatorname{gr}^{25}$. Program "1000 hari" dari masa kehamilan sampai usia 2 tahun merupakan solusi untuk mengurangi risiko obesitas yang dipengaruhi oleh kondisi di dalam janin. Undernutrisi pada periode tersebut menyebabkan gangguan kognitif dan perkembangan fisik, serta meningkatkan risiko terjadinya penyakit noncommunicable di masa dewasa. Sebaliknya, nutrisi 
yang optimal dapat mencegah masalah kesehatan di masa mendatang ${ }^{26}$. SUN (Scaling Up Nurition) yang merupakan gerakan yang mendukung rencana nasional untuk meningkatkan gizi masyarakat menempatkan fokus khususnya pada program ini.

Terdapat perbedaan asupan natrium antara kasus dan kontrol $(\mathrm{p}=0,042)$. Dalam penelitian ini asupan tinggi natrium mempunyai risiko 3,5 kali untuk mengalami hipertensi obesitas. Penelitian lainnya yaitu pada pria dan wanita Jepang menunjukkan bahwa populasi dengan asupan natrium yang tinggi lebih cenderung mengalami hipertensi $\mathrm{i}^{27}$. Natrium adalah kation utama cairan ekstraseluler sehingga mengatur volume ektraseluler dan plasma. Natrium penting dalam fungsi neuromuskular dan mempertahankan keseimbangan asam basa. ${ }^{4}$ Asupan natrium yang tinggi dapat mengakibatkan ion $\mathrm{Na}$ dalam bahan makanan diserap ke dalam pembuluh darah. Adanya ion $\mathrm{Na}$ di dalam darah akan mengakibatkan tubuh meretensi lebih banyak air untuk mempertahankan pengenceran elektrolit. $\mathrm{NaCl}$ tetap ekstraseluler sehingga cairan intestinal bisa terakumulasi dan volume plasma meningkat ${ }^{28}$. Peningkatan volume plasma dalam waktu yang lama menyebabkan peningkatan volume sekuncup yang kronis karena peningkatan volume plasma direfleksikan dengan peningkatan volume diastolik akhir sehingga volume sekuncup dan tekanan darah meningkat ${ }^{29}$.

Hubungun antara asupan natrium dan hipertensi telah banyak dipelajari, begitu pula obesitas dan hipertensi. Hasil penelitian ini sejalan dengan penelitian Bunga Puspitasari pada tahun 2009 yang menemukan bahwa asupan natrium merupakan faktor risiko paling kuat yang berhubungan dengan kejadian hipertensi ${ }^{30}$. Asupan natrium berisiko 4,359 kali mengalami hipertensi. Hasil $F F Q$ dalam penelitian ini menujukkan baik kasus dan kontrol lebih menyukai makanan dengan kandungan natrium yang tinggi. Makanan dikatakan tinggi natrium jika mengandung natrium $\geq 480 \mathrm{mg} / \mathrm{sajian}^{31}$. Penelitian di Yogyakarta secara cross-sectional menunjukkan bahwa obesitas berhubungan dengan hipertensi. Sebanyak $86,5 \%$ anak yang obese memiliki tekanan darah yang tinggi. Tekanan darah yang tinggi sejak masa kanak-kanak menyebabkan kondisi yang lebih buruk di masa mendatang. Jika kondisi ini terus terjadi, anak tersebut akan mengalami peningkatan tekanan darah pada usia dewasa yang berdampak pada peningkatan morbiditas dan mortalitas kardiovaskular dan prevalensi hipertensi di masa yang akan datang akan meningkat ${ }^{32}$.

\section{KETERBATASAN PENELITIAN}

Peneliti memiliki ketebatasan dalam menentukan status tekanan darah subyek karena nilai tekanan darah yang dikategorikan hipertensi tidak absolut, karena bergantung pada jenis kelamin, usia, dan persentil tinggi badan subyek. Selain itu, pada saat pengambilan data berat badan lahir, beberapa orang tua tidak membawa data pendukung lainnya yaitu catatan KMS/KIA.

\section{KESIMPULAN}

1. Besar risiko faktor asupan tinggi natrium terhadap kejadian hipertensi obesitas sebesar 3,5 kali dan hubungan antara asupan tinggi natrium dan hipertensi obesitas secara statistik bermakna.

2. Besar risiko faktor berat badan lahir $\geq 3500$ gr terhadap kejadian hipertensi obesitas sebesar 3,7 kali dan hubungan antara berat badan lahir dan hipertensi obesitas secara statistik bermakna.

\section{SARAN}

Hipertensi obesitas sebaiknya dicegah sejak dini dengan mencegah terjadinya gangguan pertumbuhan janin. Berat badan lahir rendah maupun tinggi mencerminkan adanya gangguan pertumbuhan janin. Oleh sebab itu, ibu sebaiknya melakukan pemeriksaan USG untuk menilai ukuran dan status kesehatan janin agar jika menemukan kelainan dapat segera ditangani. Selain itu, perlu dilakukan usaha agar siswa dapat memilih makanan yang sehat sehingga asupan natrium siswa tidak melebihi dari batas asupan normal melalui usaha kantin sehat di sekolah. Selanjutnya, perlu diteliti mengenai faktor risiko sindrom metabolik lainnya, yaitu hiperinsulinemia dan dislipidemia.

\section{DAFTAR PUSTAKA}

1. Desmita. Psikologi Perkembangan. Bandung: Remaja Rosdakarya; 2006 Hal. 190

2. Evi H. Kebiasaan Makan Remaja. skripsi. Jakarta: Universitas Indonesia; 2009.

3. Odgen CL, Flegal MK. Changes in Terminology for Childhood Overweight and Obesity [serial online] [cited 2010 jun 25]; 25. CDC; 2010 Available from: URL: HYPERLINK http://www.cdc.gov/nchs/data/nhsr/nhsr025.pdf

4. Krummel DA, Couch SC. Medical nutrition therapy in hypertension. Dalam : Maham K, Escott-Stump S. Krause's food, nutrition \& diet therapy. $12^{\text {th }}$ edition. St Louis: Saunders Elsevier;2008.p866-74. 
5. Davy KP, John EH. Obesity and hypertension : two epidemics or one? Am J Physiol 2004; 286: R803-R813

6. Sorof JM, Urbina EM, Cunningham RJ, Hogg RJ, Moxey-Mims M, Eissa MA, Rolf C. Screening for eligibility in the study of antihypertensive medication in children: experience from the Ziac Pediatric Hypertension Study. Am J Hypertens. 2001;14:783-87.

7. Sacks FM et al. Effect on blood pressure of reduced dietary sodium and the dietary approaches to stop hypertension (DASH) diet. N Engl J Med 2001 Jan 4, 344 (1):3-10

8. S Danielzik, M Czerwinski-Mast, K Langnase, B Dilba and MJ Muller. Parental overweight, socioeconomic status and high birth weight are the major determinants of overweight and obesity in 5-7 y-old children: baseline data of the Kiel Obesity Prevention Study (KOPS). International Journal of Obesity 2004;28:1494-1502

9. Barker DJP. Birth weight and hypertension. Hypertension. 2006;48:357-58

10. De Boo HA, Harding JE. The developmental origins of adult disease (Barker) hypothesis. Australian and New Zealand Journal of Obstetrics and Gynaecology. 2006;46: 4-14

11. J-Y Tian et al. Birth weight and risk of type 2 diabetes, abdominal obesity and hypertension among Chinese adults. European Journal of Endocrinology 2006; 155:601-7

12. Mashid Dehghan, Noori Akhtar-Danesh, Anwar T Merchant. Childhood obesity, prevalence, and prevention. Nutrition Journal 2005; 24:1-8

13. Badan Litbang Kesehatan Departemen Kesehatan RI. Berat Badan Lahir. Riset Kesehatan Dasar (RISKESDAS) 2010. http://www.depkes.go.id, 1 Desember 2010

14. Christianus WH. Hubungan tingkat hipertensi dengan kejadian mikroalbuminuria pada anak obesitas usia 12-14 tahun. Tesis. Semarang: Universitas Diponegoro; 2007

15. Sudigdo S, Sofyan I. Dasar-Dasar Metodologi Penelitian Klinis. Edisi 3. Jakarta : CV Sagung Seto; 2008

16. Luma GB, Spiotta RT. Hypertension in Children and adolescents. American Fam Physician 2006 May 1, 73 (9):1558-68

17. Fatemeh Moghaddam Tabrizi and G Saraswathi. Maternal anthropometric measurements and other factors: relation with birth weight of neonates. Nutr Res Pract 2012;6(2):132-37

18. Gidding SS et al. Dietary Recomendation for children and adolescents : a guide for practitioners : consensus statement from the American Heart Association. Circulation. 2005; 112:2061-75.

19. Supariasa. Penilaian Status Gizi. Jakarta: EGC; 2002

20. M. Sopiyudin Dahlan. Statistik untuk Kedokteran dan Kesehatan. Jakarta: Salemba Medika; 2009
21. Pietilainen KH, Kaprio J, Rasanen M, Rissanen A, Rose RJ. Genetic and Enviromental Influences on the Tracking of Body Size from Birth to Early Adulthood. Obesity Research 2002; 10 (9): 875884

22. Labayen I et al. Early Programming of Body Composition and Fat Distribution in Adolescents. J.Nutr. 2006; 136: 147-152

23. Wells JCK, Chomtho $\mathrm{S}$ and Fewtrell MS. Programming of body composition by early growth and nutrition. Proceedings of the Nutrition Society 2007; 66: 423434

24. Jung-Nan Wei et al. Birth Weight Correlates Differently with Cardiovascular Risk Factors in Youth. Obesity 2007; 15 (6): 1609-16

25. Jung-Nan Wei et al. Low Birth Weight and High Birth Weight Infants are Both at an Increased Risk to Have Type 2 Diabetes Among Schoolchildren in Taiwan. Diabetes Care 2003; 26:243-248

26. 1000 Days to Change the Future. Scaling Up Nutrition. http.//www.scalingupnutrition.org. January 25, 2012

27. Chisato N, Naoyoshi T, Natsuki S, Hiroyuki S. Sodium Intake and Risk of Death from Stroke in Japanese Men and Women. Stroke. 2004;35:15431547

28. Maria C Linder. Biokimia Nutrisi dan Metabolisme. Jakarta: Universitas Indonesia: 2006

29. Yudha KE, Esty Wahyuningsih, Dewi Yulianti, Pamilih Eko Karyuni, editors. Handbook of pathophysiology. USA : Lippincott Williams \& Wilkins; 2008

30. Bunga P. Asupan zat gizi mikro dan makro pada remaja. KTI. Semarang: Universitas Diponegoro; 2009.

31. Drewnowski Adam. Concept of a nutritious food: toward a nutrient density score. Am J Clin Nutr 2005;82:721-32.

32. Emy H, Madarina J. Tekanan darah siswa sekolah dasar obes dan tidak obes di kota Yogyakarta. Jurnal Gizi Klinik Indonesia. 2009; 6(2): 60-63 